\title{
Preventive and therapeutic significance of octreotide combined with lansoprazole on post-ERCP pancreatitis and its effect on serum amylase, inflammatory factors and immune function
}

\author{
ZHILIANG CHEN ${ }^{1}$, HONG FU $^{1}$, JIANFENG FANG ${ }^{1}$, JIANHUI YANG $^{1}$, \\ $\mathrm{XIN}_{\mathrm{ZHU}}{ }^{1}$, BINGXIANG CHENG ${ }^{1}$ and TIANNV DING ${ }^{2}$ \\ ${ }^{1}$ Department of Hepatobiliary Surgery and ${ }^{2}$ Endoscopy Center, Shaoxing People's Hospital \\ (Shaoxing Hospital, Zhejiang University School of Medicine), Shaoxing, Zhejiang 312000, P.R. China
}

Received July 10, 2019; Accepted July 30, 2020

DOI: $10.3892 /$ etm.2021.9682

\begin{abstract}
The study aimed to investigate the preventive and therapeutic significance of octreotide combined with lansoprazole on post-endoscopic retrograde cholangiopancreatography (ERCP) pancreatitis (PEP) and its effects on serum amylase (AMS), inflammatory factors and immune function. A total of 132 patients who underwent ERCP in Shaoxing People's Hospital (Shaoxing, China) were enrolled in the study and allocated into two groups: The study group (octreotide plus lansoprazole, 68 cases) and the control group (octreotide alone, 64 cases). The incidence of PEP and post-ERCP hyperamylasemia (PEH), the concentrations of serum AMS, interleukin-17 (IL-17) and tumor necrosis factor- $\alpha$ (TNF- $\alpha)$, as well as the T-lymphocyte population in peripheral blood were detected. The AMS levels in the study group were significantly lower than those in the control group at 6 and $24 \mathrm{~h}$ after treatment $(\mathrm{P}<0.001)$. The incidence of PEP and PEH, symptom disappearance time and hospital stay in the study group were significantly lower than those in the control group after treatment $(\mathrm{P}<0.05)$. The levels of IL-17 and TNF- $\alpha$ in the study group were significantly lower than those in the control group after treatment (all $\mathrm{P}<0.05)$. The percentage of $\mathrm{CD}^{+}, \mathrm{CD}^{+}, \mathrm{CD}^{+}$cells and the ratio of $\mathrm{CD}^{+} / \mathrm{CD}^{+}$in the study group were significantly higher than those in the control group after treatment (all $\mathrm{P}<0.05)$. The results indicated that octreotide combined with lansoprazole reduces AMS levels and the incidence of PEP, alleviates inflammation and improves the immune function.
\end{abstract}

Correspondence to: Dr Hong Fu, Department of Hepatobiliary Surgery, Shaoxing People's Hospital (Shaoxing Hospital, Zhejiang University School of Medicine), 568 Zhongxin Bei Road, Yuecheng, Shaoxing, Zhejiang 312000, P.R. China

E-mail: frx21r@163.com; zjufh@163.com

Key words: octreotide, lansoprazole, endoscopic retrograde cholangiopancreatography, pancreatitis

\section{Introduction}

Endoscopic retrograde cholangiopancreatography (ERCP) is one of the most important methods for clinical diagnosis and treatment of biliary and pancreatic diseases (1). ERCP assists in the implementation of surgeries and the ERCP indications are increasing (2). However, it is a traumatic and invasive examination that may cause pancreatitis, hyperamylasemia, hemorrhage, perforation and other complications. Among them, post-ERCP pancreatitis (PEP) is the most common one, with an incidence rate of 7.7-10\% (3-5). PEP patients without timely treatment are prone to develop severe acute pancreatitis, which may even lead to death in severe cases (6). Therefore, avoiding its occurrence is of great significance.

Clinically, conventional drugs for the prevention and treatment of PEP and post-ERCP hyperamylasemia (PEH) include somatostatin analogs and calcium channel blockers $(7,8)$. Octreotide is a kind of synthetic somatostatin analogue that inhibits the secretion of pituitary, pancreas and gastrointestinal hormones (9). Although some progress has been made in the prevention of PEP by octreotide, the effect of the monotherapy is still unsatisfactory (10). As a new proton pump inhibitor (PPI), lansoprazole is effective in treating the gastroesophageal reflux disease and peptic ulcer (11); however, its effect on the prevention and treatment of PEP has hardly been investigated. In addition, inflammatory factors, such as interleukin-17 (IL-17) and tumor necrosis factor- $\alpha$ (TNF- $\alpha$ ), increase gradually in the early stages of pancreatitis. TNF- $\alpha$ activates the lysozyme system, thus damaging pancreatic cells and participating in the progression of pancreatitis $(12,13)$. Moreover, surgical trauma and anesthesia may cause disorders of the immune function, and low immune function is closely related to the development of pancreatitis (14).

Up to our knowledge, only a few previous studies have been reported on the preventive and therapeutic effects of octreotide combined with lansoprazole on PEP. Therefore, in the present study, the combination therapy was used to treat patients undergoing ERCP in order to explore its effects on PEP, serum amylase (AMS), inflammatory factors and immune function. 


\section{Patients and methods}

General data. In this observational study, a total of 132 patients who underwent ERCP in Shaoxing People's Hospital (Shaoxing, China) from March, 2012 to June, 2015 were enrolled and allocated into two groups: The study group (treated with octreotide plus lansoprazole, 68 cases) and the control group (treated with octreotide alone, 64 cases). In the study group, there were 37 male and 31 female patients, aged 24-75 years with an average age of $59.4 \pm 10.1$ years. In the control group, there were 36 male and 28 female patients, aged 22-74 years with an average age of 58.1 \pm 9.8 years. The study was approved by the Ethics Committee of Shaoxing People's Hospital (1536-40-16). Signed written informed consents were obtained from the patients and/or guardians.

Inclusion and exclusion criteria. Inclusion criteria: Patients who met the ERCP indications and the study followed the Strengthening the Reporting of Observational Studies in Epidemiology (STROBE) Statement guidelines; patients with complete clinical data, and aged 22-75 years. Exclusion criteria: Patients with surgical and anesthetic intolerance, or contraindications to drugs applied in this treatment; patients with previous hyperamylasemia or pancreatitis; patients receiving anti-inflammatory, immunosuppressive and non-steroidal anti-infection drugs in the past month; patients with abnormal coagulation function; patients with cognitive dysfunction and mental diseases; patients complicated with digestive tract ulcer, heart failure, respiratory failure, malignant tumor, hemorrhage, perforation, severe cardiovascular and cerebrovascular diseases, autoimmune diseases, connective tissue diseases, or liver and kidney dysfunctions.

Treatment methods. All patients received routine intramuscular injection of $10 \mathrm{mg}$ of scopolamine (H41021048; Zhengzhou Suicheng Pharmaceutical Co., Ltd.), $50 \mathrm{mg}$ of pethidine (H63020021; Qinghai Pharmaceutical Co., Ltd.), $10 \mathrm{mg}$ of diazepam (H31021864; Shanghai Xudong Haipu Pharmaceutical Co., Ltd.) and $50 \mathrm{mg}$ of propofol (H20030115; Sichuan Guorui Pharmaceutical Co., Ltd.) before ERCP for intravenous anesthesia. Oxygen inhalation, oxygen saturation and electrocardiogram monitoring were also performed. The ERCP was conducted by physicians in accordance with the standard manual. After ERCP, rehydration, anti-infection, anti-inflammatory and other supportive treatments were given. A total of $0.1 \mathrm{mg}$ of octreotide (H120150364; Swiss Novartis Pharma Stein AG) was administered subcutaneously $1 \mathrm{~h}$ after ERCP, followed by $0.1 \mathrm{mg}$ every $8 \mathrm{~h}$ for 3 times. On this basis, the patients in the study group were given intravenous drip of $30 \mathrm{mg}$ of lansoprazole (H20100055; Shandong Luoxin Pharmaceutical Co., Ltd.) and $0.9 \%$ normal saline $(100 \mathrm{ml}) 1 \mathrm{~h}$ after ERCP, twice per day. The drip was completed within $30 \mathrm{~min}$ and the treatment was carried out for 7 consecutive days.

Evaluation indices. The incidence rates of PEP and PEH in the two groups were recorded. According to the diagnostic criteria of Ilone and Fauzi (15), patients with abdominal pain and tenderness at $2 \mathrm{~h}$ after ERCP, AMS levels $>3$ times higher than the normal upper limit, typical pancreatitis-like abdominal pain over $24 \mathrm{~h}$ and severe pain requiring hospitalization were diagnosed with PEP. PEH was diagnosed in patients whose serum AMS levels exceeded the normal value without the above clinical signs. The symptom disappearance time and hospital stay in the two groups were recorded.

Outcome measures. A total of $3 \mathrm{ml}$ of venous blood were drawn before treatment, and at 6 and $24 \mathrm{~h}$ after treatment, respectively, and placed in vacuum tubes without anticoagulant. Additional 3-ml samples were collected $24 \mathrm{~h}$ after treatment and placed in a vacuum tube containing EDTA.

DxC 600 automatic biochemical analyzer (Beckman Coulter, Inc.) was used to detect AMS (702; Beijing Bioassay Technology Laboratory) levels before treatment, and at 6 and $24 \mathrm{~h}$ after treatment.

The levels of serum IL-17 and TNF- $\alpha$ in the two groups, before treatment and at $24 \mathrm{~h}$ after treatment, were measured by ELISA (kits purchased from Shanghai Xinfan Biotechnology Co., Ltd.; XF-HUMAN-0979 and XF-HUMAN-1140) (16). A standard well, a testing well and a blank control well (with no sample and ELISA kit) were set up. A 2-fold diluted standard (50 $\mu \mathrm{l})$ was added into the standard well and $50 \mu \mathrm{l}$ of sample were added into the testing well. After the addition of $50 \mu \mathrm{l}$ of diluted antibody to each well, the plate was sealed and incubated for $2 \mathrm{~h}$. Next, the liquid in each well was discarded, the well was repeatedly washed for 6 times and dried. A total of $100 \mu \mathrm{l}$ of diluted horseradish peroxidase-labeled streptavidin were added to each well and the plate was incubated for $45 \mathrm{~min}$. The liquid in each well was then discarded, the well was repeatedly washed for 6 times and dried. Afterwards, $100 \mu 1$ of chromogenic substrate TMB solution were added to each well and incubated in the dark for 5 min. Finally, $100 \mu \mathrm{l}$ of stop solution were added. The optical density was measured at a wavelength of $450 \mathrm{~nm}$ using Multiskan MK3 microplate reader (Shanghai Thermo Fisher Scientific, Inc.) and the IL-17 and TNF- $\alpha$ levels were measured.

FACSCanto flow cytometer (BD Biosciences) was employed to detect the T-lymphocyte population in peripheral blood before treatment and at $24 \mathrm{~h}$ after treatment. A total of $20 \mu \mathrm{l}$ from $1 \mathrm{ml}$ of EDTA-treated peripheral venous blood was added into an Tru COUNT tube containing known quantities of freeze-dried standard fluorescent microspheres. The mixture was incubated with mouse anti-human monoclonal antibodies conjugated with fluorescein isothiocyanate (FITC) or phycoerythrin (PE): Anti-CD3-PE, anti-CD4-FITC, anti-CD8-PE (Shanghai Hengfei Biological Technology Co., Ltd.; cat. nos. 130-103-130, 130-109-536, 130-098-078, $5 \mu 1$ each) in the dark at room temperature for $15 \mathrm{~min}$. Following a reaction with red blood cell lysate $(450 \mu \mathrm{l})$ for $15 \mathrm{~min}$, a flow cytometer was used to measure the sample and CELLQUEST software (Becton-Dickinson) was used to analyze the percentages of $\mathrm{CD}^{+}, \mathrm{CD}^{+}$and $\mathrm{CD} 8^{+}$cells.

Statistical analysis. SPSS 22.0 software (Guangzhou Coslan Instrument Co., Ltd.) was used for the statistical analysis of the data. Measurement data were expressed as the mean \pm standard deviation (mean $\pm \mathrm{SD}$ ), and the intergroup comparison was conducted by independent samples t-test, whereas the intragroup comparison was conducted by paired t-test. Count data were expressed by the number of cases and percentage [n (\%)] and the intergroup comparison between groups was 
Table I. Patient general data in the study and control groups [n (\%), mean \pm SD] .

\begin{tabular}{|c|c|c|c|c|}
\hline Characteristics & Study group $(\mathrm{n}=68)$ & Control group $(\mathrm{n}=64)$ & $\mathrm{t} / \chi^{2}$ value & P-value \\
\hline Sex & & & 0.045 & 0.832 \\
\hline Male & $37(54.41)$ & $36(56.25)$ & & \\
\hline Female & $31(45.59)$ & $28(43.75)$ & & \\
\hline Age (years) & $59.4 \pm 10.1$ & $58.1 \pm 9.8$ & 0.750 & 0.455 \\
\hline $\operatorname{BMI}\left(\mathrm{kg} / \mathrm{m}^{2}\right)$ & $23.57 \pm 3.48$ & $23.78 \pm 3.22$ & 0.359 & 0.720 \\
\hline Disease type & & & 0.870 & 0.351 \\
\hline Choledocholithiasis & $46(67.65)$ & $48(75.00)$ & & \\
\hline Obstructive jaundice & $22(32.35)$ & $16(25.00)$ & & \\
\hline ERCP duration (min) & $31.12 \pm 8.13$ & $30.27 \pm 8.15$ & 0.600 & 0.550 \\
\hline Hypertension & & & 0.005 & 0.945 \\
\hline Yes & $3(4.41)$ & $2(3.12)$ & & \\
\hline No & $65(95.59)$ & $62(96.88)$ & & \\
\hline Diabetes & & & 0.244 & 0.621 \\
\hline Yes & $2(2.94)$ & $4(6.25)$ & & \\
\hline No & $66(97.06)$ & $60(93.75)$ & & \\
\hline Duodenal diverticulum & & & 0.495 & 0.482 \\
\hline Yes & $15(22.06)$ & $11(17.19)$ & & \\
\hline No & $53(77.94)$ & $53(82.81)$ & & \\
\hline Smoking history & & & 0.238 & 0.625 \\
\hline Yes & $29(42.65)$ & $30(46.88)$ & & \\
\hline No & $39(57.35)$ & $34(53.12)$ & & \\
\hline Drinking history & & & 0.535 & 0.465 \\
\hline Yes & $35(51.47)$ & $37(57.81)$ & & \\
\hline No & $33(48.53)$ & $27(42.19)$ & & \\
\hline Balloon dilation & & & 1.072 & 0.300 \\
\hline Dilated & $40(58.82)$ & $45(70.31)$ & & \\
\hline Undilated & $28(41.18)$ & $19(29.69)$ & & \\
\hline White blood cells (x109/1) & $6.07 \pm 2.02$ & $5.86 \pm 1.72$ & 0.641 & 0.523 \\
\hline Platelets $\left(\times 10^{9} / \mathrm{l}\right)$ & $153.46 \pm 32.69$ & $162.58 \pm 35.51$ & 1.536 & 0.127 \\
\hline Residence & & & 0.189 & 0.664 \\
\hline Urban & $46(67.65)$ & $41(64.06)$ & & \\
\hline Rural & $22(32.35)$ & $23(35.94)$ & & \\
\hline
\end{tabular}

BMI, body mass index; ERCP, endoscopic retrograde cholangiopancreatography.

conducted by Chi-square test. The data of multiple time points were analyzed by repeated measures analysis of variance, and LSD-t-test was the post-hoc text used for pairwise comparisons. $\mathrm{P}<0.05$ was considered to indicate a statistically significant difference.

\section{Results}

Patient general data in the two groups. There was no significant difference in sex, age, body mass index (BMI), disease type, ERCP duration, hypertension, diabetes, duodenal diverticulum, smoking history, drinking history, balloon dilatation, white blood cells, platelets and residence between the two groups $(\mathrm{P}>0.05$; Table I).

Serum AMS levels in the two groups at different time points. In the study group, the serum AMS levels before treatment, at 6 and $24 \mathrm{~h}$ after treatment were 59.24 $\pm 17.02,104.32 \pm 20.31$ and $97.12 \pm 14.32 \mathrm{U} / 1$, respectively, whereas those in the control group were $58.74 \pm 15.32,183.65 \pm 17.43$ and $166.32 \pm 21.53 \mathrm{U} / 1$, respectively. Thus, the serum AMS levels in the two groups at $6 \mathrm{~h}$ after treatment were significantly higher than those before treatment $(\mathrm{P}<0.001)$. The levels decreased significantly at $24 \mathrm{~h}$ after treatment compared with those at $6 \mathrm{~h}$ after treatment $(\mathrm{P}<0.001)$; however, they remained higher than those before treatment $(\mathrm{P}<0.001)$. There was no significant difference in serum AMS levels between the study and the control group before treatment $(\mathrm{P}>0.05)$. AMS expression in the study group was significantly lower than that in the control group at 6 and $24 \mathrm{~h}$ after treatment $(\mathrm{P}<0.001)$. Data are shown in Fig. 1.

Incidence of PEP and PEH in the two groups. In the study group, PEP occurred in 1 case $(1.47 \%)$ and PEH occurred 
Table II. Comparison of incidence of pancreatitis and hyperamylasemia between the two groups [n (\%)].

\begin{tabular}{lccc}
\hline Group & $\mathrm{n}$ & Pancreatitis & Hyperamylasemia \\
\hline Study group & 68 & $1(1.47)$ & $12(17.65)$ \\
Control group & 64 & $6(9.38)$ & $23(35.94)$ \\
$\chi^{2}$ value & - & 2.338 & 5.661 \\
P-value & - & 0.021 & 0.017 \\
\hline
\end{tabular}

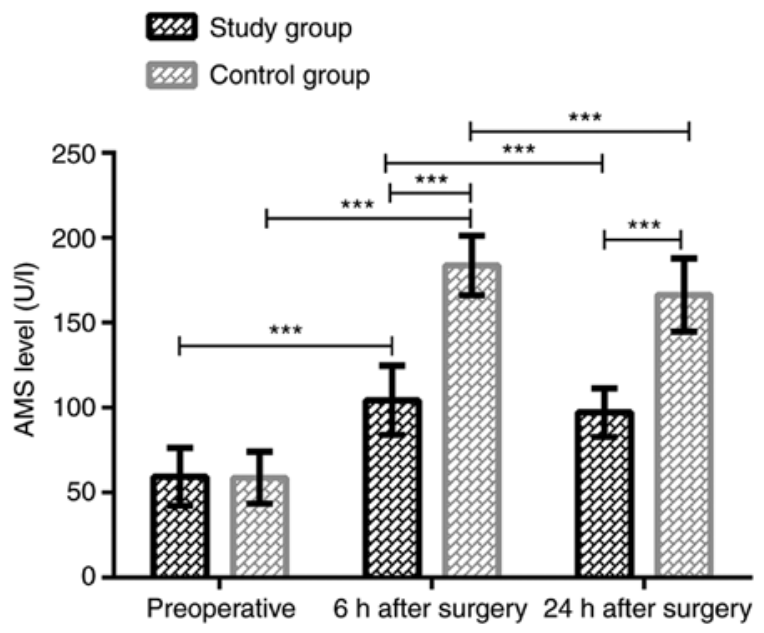

Figure 1. Comparison of serum AMS levels between the study and the control group at different time points. The serum AMS levels in the two groups at $6 \mathrm{~h}$ after treatment were significantly higher than those before treatment $(\mathrm{P}<0.001)$. At $24 \mathrm{~h}$ after treatment, the AMS levels decreased significantly compared with those at $6 \mathrm{~h}$ after treatment $(\mathrm{P}<0.001)$; however, they remained higher than those before treatment $(\mathrm{P}<0.001)$. There was no significant difference in serum AMS levels between the study and the control group before treatment $(\mathrm{P}>0.05)$. AMS levels were significantly lower in the study group than those in the control group at 6 and $24 \mathrm{~h}$ after treatment $(\mathrm{P}<0.001) .{ }^{* * *} \mathrm{P}<0.001$. AMS, amylase.

in 12 cases $(17.65 \%)$. In the control group, PEP occurred in 6 cases $(9.38 \%)$ and $\mathrm{PEH}$ in 23 cases $(35.94 \%)$. The incidence of postoperative PEP and PEH in the study group was significantly lower than that in the control group $(\mathrm{P}<0.05)$. Data are presented in Table II.

Serum IL-17 levels in the two groups before and after treatment. The serum IL-17 levels in the study group before and at $24 \mathrm{~h}$ after treatment were $6.62 \pm 2.31$ and $7.51 \pm 2.04 \mathrm{pg} / \mathrm{ml}$, respectively. In the control group, IL-17 levels were $6.45 \pm 2.58$ and $9.04 \pm 2.75 \mathrm{pg} / \mathrm{ml}$, respectively. There was no significant difference in serum IL-17 levels between the two groups before treatment $(\mathrm{P}>0.05)$. At $24 \mathrm{~h}$ after treatment, the IL-17 expression was significantly increased in both groups $(\mathrm{P}<0.05)$, and in the study group, IL-17 expression was significantly lower than that in the control group $(\mathrm{P}<0.001)$. Data are shown in Fig. 2.

Serum TNF- $\alpha$ levels in the two groups before and after treatment. The serum TNF- $\alpha$ levels in the study group were $74.35 \pm 25.72 \mathrm{pg} / \mathrm{ml}$ before treatment and $82.29 \pm 17.18 \mathrm{pg} / \mathrm{ml}$ at $24 \mathrm{~h}$ after treatment, whereas in the control group were

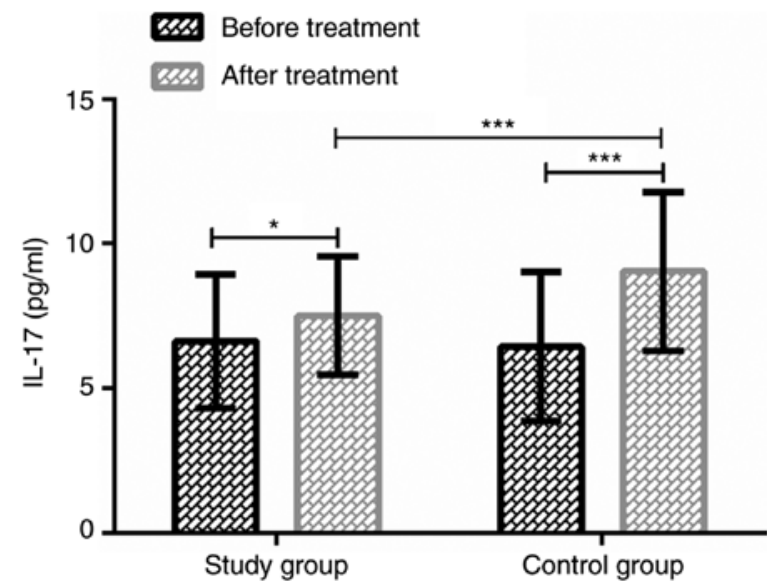

Figure 2. Comparison of serum IL-17 levels between the two groups before and after treatment. There was no significant difference in serum IL-17 levels between the two groups before treatment $(\mathrm{P}>0.05)$. At $24 \mathrm{~h}$ after treatment, the levels in the two groups were significantly increased $(\mathrm{P}<0.05)$, and IL-17 expression in the study group was significantly lower than that in the control group $(\mathrm{P}<0.001) .{ }^{*} \mathrm{P}<0.05,{ }^{* * *} \mathrm{P}<0.001$. IL-17, interleukin-17.

$76.13 \pm 18.91$ and $89.73 \pm 24.32 \mathrm{pg} / \mathrm{ml}$, respectively. There was no significant difference in serum TNF- $\alpha$ levels between the two groups before treatment $(\mathrm{P}>0.05)$. After treatment, the TNF- $\alpha$ expression was significantly increased in both groups $(\mathrm{P}<0.05)$, and in the study group, TNF- $\alpha$ expression was significantly lower than that in the control group $(\mathrm{P}<0.05)$. Data are shown in Fig. 3.

T-lymphocyte population in the two groups before and after treatment. There was no significant difference in the percentages of $\mathrm{CD}^{+}, \mathrm{CD}^{+}$and $\mathrm{CD}^{+}$cells and the $\mathrm{CD}^{+} / \mathrm{CD}^{+}$ratio in peripheral blood between the two groups before treatment (P>0.05). At $24 \mathrm{~h}$ after treatment, the values of $\mathrm{CD}^{+}, \mathrm{CD}^{+}$, $\mathrm{CD}^{+}$and $\mathrm{CD}^{+} / \mathrm{CD}^{+}$in both groups were significantly decreased $(\mathrm{P}<0.05)$, and in the study group were significantly higher than those in the control group $(\mathrm{P}<0.05)$ (Table III and Fig. 4).

Symptom disappearance time and hospital stay in the two groups. The symptom disappearance time and hospital stay in the study group were significantly lower than those in the control group $(\mathrm{P}<0.001)$ (Table IV).

\section{Discussion}

ERCP is an important method for the treatment of biliary and pancreatic diseases that not only cures the disease, but also relieves the pain of patients caused by surgical trauma to the greatest extent (17). However, even with the continuous development of ERCP technology, patients still suffer from PEP, $\mathrm{PEH}$ and other complications (18).

Previous studies on octreotide in the prevention of PEP are numerous. For example, Thomopoulos et al (19) have pointed out that octreotide may reduce the incidence of PEP. Moreover, in a multi-center randomized controlled trial by Bai et al (20), prophylactic use of somatostatin (octreotide) was shown to decrease the incidence of PEP. However, Binmoeller et al (21) showed that octreotide may have no 
Table III. Comparison of T-lymphocyte populations in peripheral blood between the two groups (mean \pm SD).

\begin{tabular}{|c|c|c|c|c|}
\hline Group & Study group $(n=68)$ & Control group $(\mathrm{n}=64)$ & $\mathrm{t}$ value & P-value \\
\hline \multicolumn{5}{|l|}{$\mathrm{CD}^{+}(\%)$} \\
\hline Before treatment & $63.13 \pm 4.65$ & $63.07 \pm 4.75$ & 0.073 & 0.942 \\
\hline After treatment $(24 \mathrm{~h})$ & $57.76 \pm 4.66$ & $54.65 \pm 4.82$ & 3.769 & $<0.001$ \\
\hline $\mathrm{t}$ value & 6.727 & 9.954 & - & - \\
\hline P-value & $<0.001$ & $<0.001$ & - & - \\
\hline \multicolumn{5}{|l|}{$\mathrm{CD}^{+}(\%)$} \\
\hline Before treatment & $36.53 \pm 4.42$ & $35.67 \pm 4.31$ & 1.131 & 0.260 \\
\hline After treatment $(24 \mathrm{~h})$ & $34.02 \pm 4.15$ & $31.16 \pm 4.23$ & 3.920 & $<0.001$ \\
\hline t value & 3.414 & 5.975 & - & - \\
\hline P-value & $<0.001$ & $<0.001$ & - & - \\
\hline \multicolumn{5}{|l|}{$\mathrm{CD}^{+}(\%)$} \\
\hline Before treatment & $25.61 \pm 3.32$ & $26.39 \pm 3.15$ & 1.383 & 0.168 \\
\hline After treatment $(24 \mathrm{~h})$ & $24.37 \pm 3.17$ & $23.16 \pm 3.08$ & 2.222 & 0.028 \\
\hline $\mathrm{t}$ value & 2.228 & 5.951 & - & - \\
\hline P-value & 0.028 & $<0.001$ & - & - \\
\hline \multicolumn{5}{|l|}{$\mathrm{CD}^{+} / \mathrm{CD}^{+}$} \\
\hline Before treatment & $1.51 \pm 0.23$ & $1.45 \pm 0.23$ & 1.498 & 0.137 \\
\hline After treatment $(24 \mathrm{~h})$ & $1.34 \pm 0.18$ & $1.25 \pm 0.28$ & 2.210 & 0.029 \\
\hline t value & 4.800 & 4.416 & - & - \\
\hline P-value & $<0.001$ & $<0.001$ & - & - \\
\hline
\end{tabular}

Table IV. Symptom disappearance time and hospital stay in the two groups (mean $\pm \mathrm{SD})$.

\begin{tabular}{|c|c|c|c|}
\hline Group & $\mathrm{n}$ & $\begin{array}{c}\text { Symptom } \\
\text { disappearance } \\
\text { time (days) }\end{array}$ & $\begin{array}{c}\text { Hospital stay } \\
\text { (days) }\end{array}$ \\
\hline Study group & 68 & $1.6 \pm 1.3$ & $12.7 \pm 1.2$ \\
\hline Control group & 64 & $3.5 \pm 3.2$ & $14.6 \pm 1.4$ \\
\hline t value & - & 4.517 & 8.387 \\
\hline P-value & - & $<0.001$ & $<0.001$ \\
\hline
\end{tabular}

preventive effect on PEP. The development of PEP is closely related to the increase of gastric acid. Abnormally increased gastric acid enters the inner wall of small intestine and duodenum, resulting in high pressure in pancreatic duct, leading to edema and necrosis of pancreas (22). Therefore, inhibiting gastric acid secretion may also be the key to prevent PEP (23). Lansoprazole is a PPI, another clinical drug to prevent PEP, that is widely used in the treatment of peptic ulcer and other acid-related gastrointestinal diseases by reducing gastric acid secretion (24). Up to our knowledge, there has been no previous report on the prevention and treatment of PEP by octreotide combined with lansoprazole. The results of the present study revealed that the AMS levels in the study group were significantly lower than those in the control group at 6 and $24 \mathrm{~h}$ after ERCP, and the incidence of PEP and PEH, symptom disappearance time and hospital stay in the study group were significantly lower than those in the control group. These indicate that octreotide

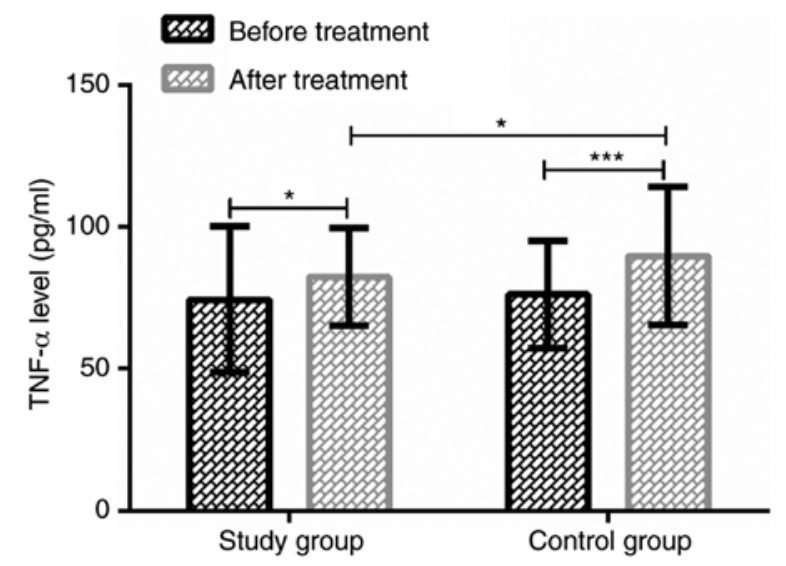

Figure 3. Comparison of serum TNF- $\alpha$ levels between the two groups before and after treatment. There was no significant difference in serum TNF- $\alpha$ levels between the two groups before treatment $(\mathrm{P}>0.05)$. At $24 \mathrm{~h}$ after treatment, the levels in the two groups were significantly increased $(\mathrm{P}<0.05)$, and TNF- $\alpha$ expression in the study group was significantly lower than that in the control group $(\mathrm{P}<0.05)$. ${ }^{*} \mathrm{P}<0.05,{ }^{* * *} \mathrm{P}<0.001$. TNF- $\alpha$, tumor necrosis factor- $\alpha$.

combined with lansoprazole reduces AMS levels and the incidence of PEP, and accelerates patient recovery. The study of Yoo et al (25) showed that PPIs have no effect on the clinical progress of acute pancreatitis. In addition, in the study of Alhazzani et al (26), PPIs and histamine 2 receptor antagonists were reported to prevent stress ulcer in critically ill patients. This suggests that lansoprazole inhibits gastric acid secretion, leading to the reduction of pancreatin and pancreatic secretion (27), thus decreasing the incidence of PEP. Therefore, octreotide combined with lansoprazole plays a preventive role in PEP. 
A

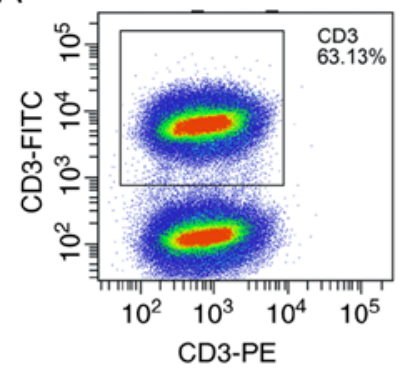

B

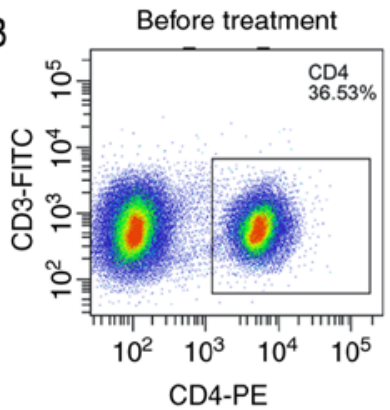

C

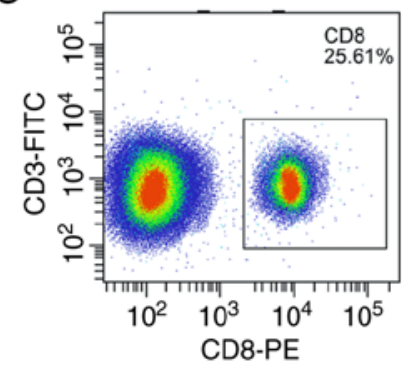

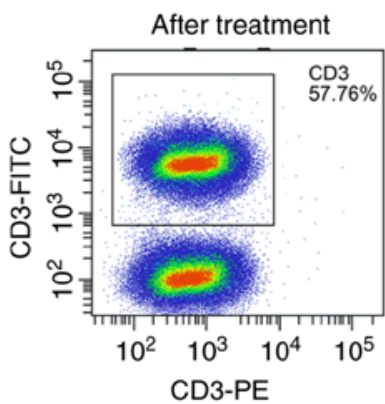

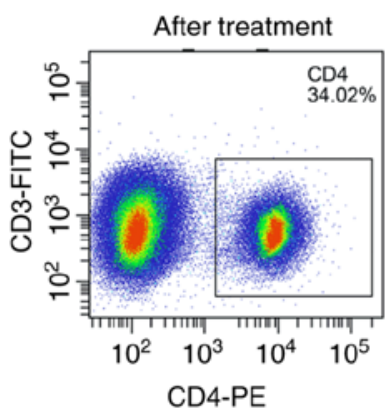

CD4-PE

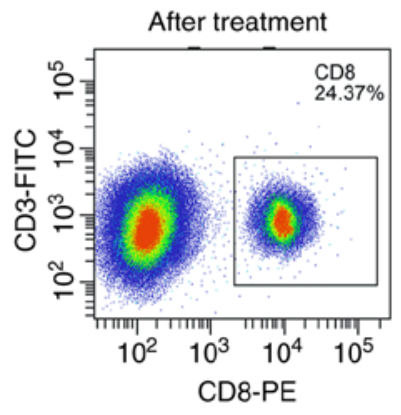

Study group
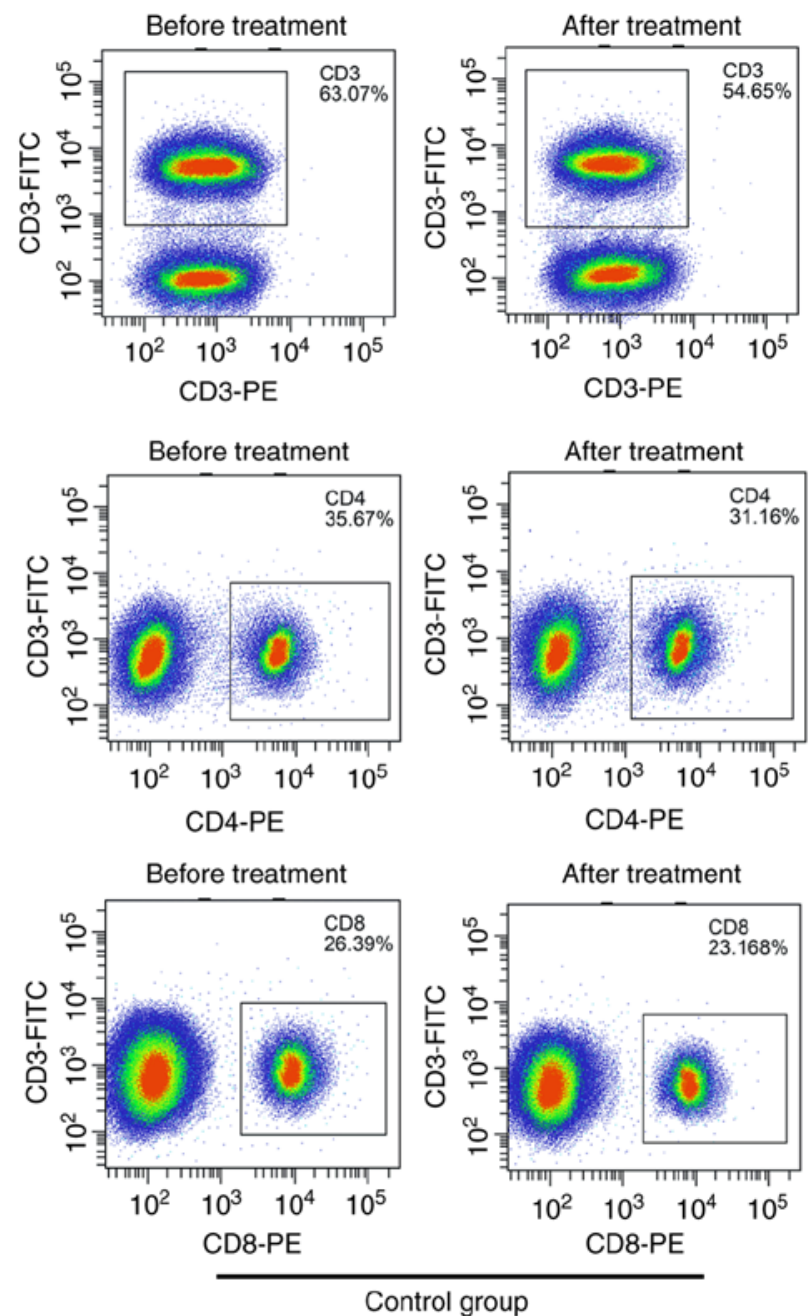

Figure 4. T-lymphocyte subsets in peripheral blood before and after treatment. The dot plots of $(\mathrm{A}) \mathrm{CD}^{+}(\mathrm{B}) \mathrm{CD}^{+}$and $(\mathrm{C}) \mathrm{CD}^{+}$before and at $24 \mathrm{~h}$ after treatment in the two groups are presented.

The release and activation of inflammatory cytokines are not only a significant cause of pancreatitis, but also an important factor of pancreatic tissue necrosis and organ dysfunction (28). Pancreatitis increases the release of some inflammatory cytokines and leads to the over-release of IL-17, TNF- $\alpha$ and other pro-inflammatory cytokines (29). Previous studies have shown that IL-17 and TNF- $\alpha$ are overexpressed in the early stages of pancreatitis, and their levels are closely related to the severity of the disease $(27,30)$. In the present study, the levels of serum IL-17 and TNF- $\alpha$ in the study and the control groups after treatment were significantly higher than those before treatment, and the levels in the study group were significantly lower than those in the control group after treatment. These results indicate that inhibition of inflammatory cytokines may be one of the mechanisms of octreotide combined with lansoprazole in preventing and treating PEP. In the study of Wang et al (31), the levels of AMS and inflammatory cytokines TNF- $\alpha$, IL- 6 and IL- 8 in serum were significantly increased after ERCP. However, compared with octreotide monotherapy, the above levels in patients treated with octreotide combined with indomethacin were significantly decreased. Hackert et al (32) revealed that PPIs are anti-inflammatory and can reduce the progression of pancreatitis, inflammation and the expression of adhesion proteins. Therefore, inhibition of inflammatory factors may be one of its therapeutic mechanisms.

Moreover, there is an imbalance in the immune function of patients with pancreatitis, and the disorder of immune function can further induce macrophage activation and pro-inflammatory response in the early stage of pancreatitis (33). T-lymphocyte subsets are vital effector cells reflecting the immune function of the body and changes in their percentages often reflect changes in the immune function of the patients (34). T-lymphocyte subsets are separated into $\mathrm{CD}^{+}, \mathrm{CD}^{+}$and $\mathrm{CD} 8^{+}$cells according to the difference of surface $\mathrm{CD}$ molecules. In the present study, the percentages of $\mathrm{CD}^{+}, \mathrm{CD}^{+}, \mathrm{CD} 8^{+}$cells and the $\mathrm{CD} 4^{+} / \mathrm{CD} 8^{+}$ratio in the two groups after treatment were significantly lower than those before treatment, and in the study group were significantly higher than those in the control group. These results suggest that octreotide combined with lansoprazole improved the disordered immune function induced by ERCP. Vaidya et al (35) reported that octreotide has no effect on T-lymphocyte subsets in patients with thyroid-associated ophthalmopathy, whereas the research of Larussa et al (36) confirmed that lansoprazole regulates Th1/Th2 immune response of human gastric mucosa, thus improving the clinical symptoms of gastritis patients. Because lansoprazole 
inhibits inflammatory cytokines and reduces their release, it has a protective effect on the immune function. However, the mechanism need to be further investigated.

The present study confirmed that octreotide combined with lansoprazole has preventive and therapeutic effects on PEP and can improve the inflammatory factors and immune function of patients. However, there are still several limitations. For example, no randomized control trials were performed, leading to biases in our results. Besides, only changes in IL-17 and TNF- $\alpha$ were measured. In addition, lansoprazole has been reported to induce side effects, such as hypomagnesemia (37), which was not mentioned in our study. These limitations will be addressed in future studies to corroborate the conclusions of the present study.

In conclusion, octreotide combined with lansoprazole reduces serum AMS levels and the incidence of PEP, and also alleviates inflammation while improving the patients' immune function.

\section{Acknowledgements}

Not applicable.

\section{Funding}

The study is part of the Project 'Clinical Study of Indomethacin Combined with Pancreatic Duct Stent in the Prevention of Hyperamylasemia' (no. 2017B70034), supported by the Shaoxing Science and Technology Bureau, Shaoxing People's Hospital and the Shaoxing Health and Family Planning Commission.

\section{Availability of data and materials}

The datasets used and/or analyzed during the present study are available from the corresponding author on reasonable request.

\section{Authors' contributions}

ZC, HF, JF and JY conceived and designed the study. ZC, $\mathrm{XZ}, \mathrm{BC}$ and TD were responsible for the data acquisition and analysis. HF, JF and XZ were responsible for the interpretation of the data and the drafting of the manuscript. $\mathrm{ZC}$ and HF revised the manuscript critically for important intellectual content. All authors read and approved the final version of the manuscript.

\section{Ethics approval and consent to participate}

The study was approved by the Ethics Committee of Shaoxing People's Hospital (Shaoxing, China) (1536-40-16). Signed written informed consents were obtained from the patients and/or guardians.

\section{Patient consent for publication}

Not applicable.

\section{Competing interests}

The authors declare that they have no competing interests.

\section{References}

1. Parikh MP, Wadhwa V, Thota PN, Lopez R and Sanaka MR: Outcomes associated with timing of ERCP in acute cholangitis secondary to choledocholithiasis. J Clin Gastroenterol 52: e97-e102, 2018

2. Park JK, Woo YS, Noh DH, Yang JI, Bae SY, Yun HS, Lee JK, Lee KT and Lee KH: Efficacy of EUS-guided and ERCP-guided biliary drainage for malignant biliary obstruction: Prospective randomized controlled study. Gastrointest Endosc 88: 277-282, 2018.

3. Kochar B, Akshintala VS, Afghani E, Elmunzer BJ, Kim KJ, Lennon AM, Khashab MA, Kalloo AN and Singh VK: Incidence, severity, and mortality of post-ERCP pancreatitis: A systematic review by using randomized, controlled trials. Gastrointest Endosc 81: 143-149. e9, 2015.

4. ASGE Standards of Practice Committee; Chandrasekhara V, Khashab MA, Muthusamy VR, Acosta RD, Agrawal D, Bruining DH, Eloubeidi MA, Fanelli RD, Faulx AL, et al: Adverse events associated with ERCP. Gastrointest Endosc 85: 32-47, 2017

5. Ito K, Fujita N, Noda Y, Kobayashi G, Horaguchi J, Takasawa O and Obana T: Relationship between post-ERCP pancreatitis and the change of serum amylase level after the procedure. World J Gastroenterol 13: 3855-3860, 2007.

6. Dumonceau JM, Andriulli A, Elmunzer BJ, Mariani A, Meister T, Deviere J, Marek T, Baron TH, Hassan C, Testoni PA, et al: Prophylaxis of post-ERCP pancreatitis: European society of gastrointestinal endoscopy (ESGE) guideline-updated June 2014. Endoscopy 46: 799-815, 2014.

7. Hou YC, Hu Q, Huang J, Fang JY and Xiong H: Efficacy and safety of rectal nonsteroidal anti-inflammatory drugs for prophylaxis against post-ERCP pancreatitis: A systematic review and meta-analysis. Sci Rep 7: 46650, 2017.

8. Dumonceau JM, Kapral C, Aabakken L, Papanikolaou IS, Tringali A, Vanbiervliet G, Beyna T, Dinis-Ribeiro M, Hritz I, Mariani A, et al: ERCP-related adverse events: European society of gastrointestinal endoscopy (ESGE) guideline. Endoscopy 52: $127-149,2020$.

9. Lamberts SWJ and Hofland L: ANNIVERSARY REVIEW: Octreotide, 40 years later. Eur J Endocrinol 181: R173-R183, 2019.

10. Li ZS, Pan X, Zhang WJ, Gong B, Zhi FC, Guo XG, Li PM, Fan ZN, Sun WS, Shen YZ, et al: Effect of octreotide administration in the prophylaxis of post-ERCP pancreatitis and hyperamylasemia: A multicenter, placebo-controlled, randomized clinical trial. Am J Gastroenterol 102: 46-51, 2007.

11. Morgan D, Pandolfino J, Katz PO, Goldstein JL, Barker PN and Illueca M: Clinical trial: Gastric acid suppression in Hispanic adults with symptomatic gastro-oesophageal reflux disease-comparator study of esomeprazole, lansoprazole and pantoprazole. Aliment Pharmacol Ther 32: 200-208, 2010.

12. Grieco FA, Moore F, Vigneron F, Santin I, Villate O, Marselli L, Rondas D, Korf H, Overbergh L, Dotta F, et al: IL-17A increases the expression of proinflammatory chemokines in human pancreatic islets. Diabetologia 57: 502-511, 2014.

13. Paajanens H, Laato M, Jaakkola M, Pulkki K, Niinikoski J and Nordback I: Serum tumour necrosis factor compared with C-reactive protein in the early assessment of severity of acute pancreatitis. Br J Surg 82: 271-273, 1995.

14. Watanabe T, Kudo M and Strober W: Immunopathogenesis of pancreatitis. Mucosal Immunol 10: 283-298, 2017.

15. Ilone $S$ and Fauzi A: Diagnostic and prevention approach in post endoscopic retrograde cholangiopancreatography pancreatitis. Indones J Gastroenterol Hepatol Dig Endosc 17: 188-193, 2017.

16. Yang R, Masters AR, Fortner KA, Champagne DP, YanguasCasás N, Silberger DJ, Weaver CT, Haynes L and Rincon M: IL-6 promotes the differentiation of a subset of naive $\mathrm{CD} 8^{+} \mathrm{T}$ cells into IL-21-producing B helper CD8 ${ }^{+} \mathrm{T}$ cells. J Exp Med 213: 2281-2291, 2016.

17. Kurihara T, Yasuda I, Isayama H, Tsuyuguchi T, Yamaguchi T, Kawabe K, Okabe Y, Hanada K, Hayashi T, Ohtsuka T, et al: Diagnostic and therapeutic single-operator cholangiopancreatoscopy in biliopancreatic diseases: Prospective multicenter study in Japan. World J Gastroenterol 22: 1891-1901, 2016.

18. Elmunzer BJ, Serrano J, Chak A, Edmundowicz SA, Papachristou GI, Scheiman JM, Singh VK, Varadurajulu S, Vargo JJ, Willingham FF, et al: Rectal indomethacin alone versus indomethacin and prophylactic pancreatic stent placement for preventing pancreatitis after ERCP: Study protocol for a randomized controlled trial. Trials 17: 120, 2016. 
19. Thomopoulos KC, Pagoni NA, Vagenas KA, Margaritis VG, Theocharis GI and Nikolopoulou VN: Twenty-four hour prophylaxis with increased dosage of octreotide reduces the incidence of post-ERCP pancreatitis. Gastrointest Endosc 64: 726-731, 2006.

20. Bai Y, Ren X, Zhang XF, Lv NH, Guo XG, Wan XJ, Nie ZG, Han ST, Bie P, Tian DA, et al: Prophylactic somatostatin can reduce incidence of post-ERCP pancreatitis: Multicenter randomized controlled trial. Endoscopy 47: 415-420, 2015.

21. Binmoeller KF, Harris AG, Dumas R, Grimaldi C and Delmont JP: Does the somatostatin analogue octreotide protect against ERCP induced pancreatitis? Gut 33: 1129-1133, 1992.

22. Saunders JH, Cargill JM and Wormsley KG: Gastric secretion of acid in patients with pancreatic disease. Digestion 17: 365-369, 1978.

23. Kahl S and Malfertheiner P: Exocrine and endocrine pancreatic insufficiency after pancreatic surgery. Best Pract Res Clin Gastroenterol 18: 947-955, 2004.

24. Li Z, Wu C, Li L, Wang Z, Xie H, He X and Feng J: Effect of long-term proton pump inhibitor administration on gastric mucosal atrophy: A meta-analysis. Saudi J Gastroenterol 23: 222-228, 2017.

25. Yoo JH, Kwon CI, Yoo KH, Yoon H, Kim WH, Ko KH, Hong SP and Park PW: Effect of proton pump inhibitor in patients with acute pancreatitis-pilot study. Korean J Gastroenterol 60 : 362-367, 2012 (In Korean).

26. Alhazzani W, Alenezi F, Jaeschke RZ, Moayyedi P and Cook DJ: Proton pump inhibitors versus histamine 2 receptor antagonists for stress ulcer prophylaxis in critically ill patients: A systematic review and meta-analysis. Crit Care Med 41: 693-705, 2013

27. Staubli SM, Oertli D and Nebiker CA: Laboratory markers predicting severity of acute pancreatitis. Crit Rev Clin Lab Sci 52: 273-283, 2015.

28. Yang R, Tenhunen J and Tonnessen TI: HMGB1 and histones play a significant role in inducing systemic inflammation and multiple organ dysfunctions in severe acute pancreatitis. Int J Inflam 2017: 1817564, 2017.

29. Dawar FU, Xiong Y, Khattak MNK, Li J, Lin L and Mei J: Potential role of cyclophilin A in regulating cytokine secretion. J Leukoc Biol 102: 989-992, 2017.
30. Dai SR, Li Z and Zhang JB: Serum interleukin 17 as an early prognostic biomarker of severe acute pancreatitis receiving continuous blood purification. Int J Artif Organs 38: 192-198, 2015.

31. Wang J, Shen Y, Zhong Z, Wu S and Zheng L: Risk factors for post-endoscopic retrograde cholangiopancreatography (ERCP) pancreatitis and the effect of octreotide combined with nonsteroidal anti-inflammatory drugs on preventing its occurrence. Med Sci Monit 24: 8964-8969, 2018.

32. Hackert T, Tudor S, Felix K, Dovshanskiy D, Hartwig W, Simon WA and Werner J: Effects of pantoprazole in experimental acute pancreatitis. Life Sci 87: 551-557, 2010.

33. Uehara S, Gothoh K, Handa H, Tomita $\mathrm{H}$ and Tomita Y: Immune function in patients with acute pancreatitis. J Gastroenterol Hepatol 18: 363-370, 2003.

34. Zhang T, Fan Y, Liu K and Wang Y: Effects of different general anaesthetic techniques on immune responses in patients undergoing surgery for tongue cancer. Anaesth Intensive Care 42: 220-227, 2014

35. Vaidya B, Shenton BK, Stamp S, Miller M, Baister E, Andrews CD, Dickinson AJ, Perros P and Kendall-Taylor P: Analysis of peripheral blood T-cell subsets in active thyroid-associated ophthalmopathy: Absence of effect of octreotide-LAR on T-cell subsets in patients with thyroid-associated ophthalmopathy. Thyroid 15: 1073-1078, 2005.

36. Larussa T, Suraci E, Leone I, Nazionale I, Abenavoli L, Galasso O, Amorosi A, Imeneo M and Luzza F: Short-term therapy with celecoxib and lansoprazole modulates Th1/Th2 immune response in human gastric mucosa. Helicobacter 15: 449-459, 2010.

37. Chrysant SG and Chrysant GS: Adverse cardiovascular and blood pressure effects of drug-induced hypomagnesemia. Expert Opin Drug Saf 19: 59-67, 2020.

(i) $\Theta$ This work is licensed under a Creative Commons Attribution-NonCommercial-NoDerivatives 4.0 International (CC BY-NC-ND 4.0) License. 